\title{
BNP controls early load-dependent regulation of SERCA through calcineurin
}

\author{
Karl Toischer • Nils Teucher • Bernhard Unsöld • \\ Michaela Kuhn · Harald Kögler • Gerd Hasenfuss
}

Received: 25 March 2010/Revised: 20 July 2010/Accepted: 3 August 2010/Published online: 15 August 2010

(C) The Author(s) 2010. This article is published with open access at Springerlink.com

\begin{abstract}
Heart failure is characterised by reduced expression of sarcoplasmic reticulum calcium-ATPase (SERCA) and increased expression of B-type natriuretic peptide (BNP). The present study was performed to investigate causality of this inverse relationship under in vivo conditions in the transversal aortic constriction mouse model (TAC). Left ventricular SERCA-mRNA expression was significantly upregulated in TAC by $32 \%$ after $6 \mathrm{~h}$, but not different from sham after $24 \mathrm{~h}$. Serum proANP and BNP levels were increased in TAC after $24 \mathrm{~h}$ (BNP $+274 \%$, $p<0.01$; proANP $+60 \%, p<0.05)$, but only proANP levels were increased after $6 \mathrm{~h}(+182 \%, p<0.01)$. cGMP levels were only increased $24 \mathrm{~h}$ after TAC $(+307 \%$, $p<0.01$ ), but not $6 \mathrm{~h}$ after TAC. BNP infusion inhibited the increase in SERCA expression $6 \mathrm{~h}$ after TAC. In BNPreceptor-knockout animals (GC-A), the expression of SERCA was still significantly increased $24 \mathrm{~h}$ after TAC at the mRNA level by $35 \%(p<0.05)$, as well as at the protein level by $25 \%(p<0.05)$. MCIP expression as an indicator of calcineurin activity was regulated in parallel to SERCA after 6 and $24 \mathrm{~h}$. MCIP-mRNA was increased by $333 \% 6 \mathrm{~h}$ after
\end{abstract}

K. Toischer and N. Teucher contributed equally to this work.

K. Toischer · B. Unsöld · H. Kögler · G. Hasenfuss ( $\square$ )

Abteilung Kardiologie und Pneumologie,

Georg-August-Universität, Robert-Koch-Str. 40,

37075 Göttingen, Germany

e-mail: hasenfus@med.uni-goettingen.de

N. Teucher

Abteilung Herz-, Thorax- und Gefäßchirurgie,

Georg-August-Universität, Göttingen, Germany

M. Kuhn

Physiologisches Institut, Universität Würzburg,

Würzburg, Germany
TAC, but not significantly different from sham after $24 \mathrm{~h}$. In the GC-A-KO mice, MCIP-mRNA was significantly increased in TAC compared to WT after $24 \mathrm{~h}$. In mice with BNP infusion, MCIP was significantly lower $6 \mathrm{~h}$ after TAC compared to control animals. In conclusion, mechanical load leads to an upregulation of SERCA expression. This is followed by upregulation of natriuretic peptides with subsequent suppression of SERCA upregulation. Elevated natriuretic peptides may suppress SERCA expression by inhibition of calcineurin activity via activation of GC-A.

Keywords Heart failure - Load - Natriuretic peptides . SERCA · Calcineurin

\section{Introduction}

In heart failure, a reactivation of the foetal gene expression programme is observed [4]. Accordingly, the level of B-type natriuretic peptide (BNP) is increased [37], and the expression and function of calcium cycling proteins is changed [11, 23, 33]. In particular, the expression of sarcoplasmic reticulum $\mathrm{Ca}^{2+}$-ATPase (SERCA) is reduced [10]. Induction of the foetal gene programme is considered to result from increased myocardial load. However, in contrast to this general scheme of reactivation of the foetal gene programme with SERCA downregulation, we have previously demonstrated in an in vitro model that increased load immediately increases SERCA expression. Moreover, load-dependent upregulation of SERCA could be abolished by addition of exogenous BNP. This effect was transmitted via the $\mathrm{BNP}$ receptor guanylyl cyclase $\mathrm{A}(\mathrm{GC}-\mathrm{A})$, elevation of cyclic guanosine monophosphate (cGMP) and activation of protein kinase $\mathrm{G}$ (PKG) [17]. PKG has effects on contractile function [21] and on signalling mechanisms. PKG 
can inhibit calcineurin activation [8], and the preloaddependent upregulation of SERCA expression could indeed be inhibited by cyclosporine A [17].

In the present study, we evaluated the role of load and BNP on early SERCA regulation under in vivo conditions.

\section{Methods}

Animals

The investigation conforms to the Guide for the Care and Use of Laboratory Animals (NIH publication No. 85-23, revised 1996) and was performed in accordance with the ethical standards laid down in the Declaration of Helsinki 1964. For the present study, the following mice strains were used: FVBN (Charles River), NFAT-luciferase transgenic [38], GC-A-KO mice [15], muscle LIM protein knockout (MLP-KO) [2] mice and wild-type littermates. Only female mice were included in the study due to the higher mortality after Transversal aortic constriction (TAC) in male mice.

\section{Transversal aortic constriction}

Surgery was performed using a minimally invasive approach as described previously [16]. Briefly, 12-weekold female FVBN mice were anesthetised using intraperitoneal injections of ketamine and xylazine $(100 \mathrm{mg} /$ $\mathrm{kg}+5 \mathrm{mg} / \mathrm{kg}$ ). A horizontal incision at the jugulum was used to display the transversal aorta. A 27-gauge needle was tied against the aorta using a 5-0 non-absorbable suture. After removal of the 27 -gauge needle, skin was closed, and the mice were kept on a warming plate until recovery from anaesthesia. Sham animals underwent the same procedure except banding of the transversal aorta. At the end of the experiment, mice were euthanised by isofluran insufflation.

\section{Osmotic minipump application of BNP}

Osmotic minipumps (1003D, ALZET, Cupertino, CA, USA) were filled with a recombinant mouse BNP-peptide (Phoenix Pharamaceuticals, St. Jospeh, MO, USA) or a saline solution. The pump rate was $0.22 \mu \mathrm{g} \mathrm{BNP/h}$. Mice were distributed to the following four groups: group I: Sham with saline infusion; group II: Sham with BNP infusion; group III: TAC with saline infusion; group IV: TAC with BNP infusion. The minipumps were primed and implanted $12 \mathrm{~h}$ before the TAC operation. The hearts of the animals were excised $6 \mathrm{~h}$ after the operation and harvested in liquid nitrogen.
Echocardiography

A 2D-guided M-mode echocardiography was performed using a VS-VEVO 660/230 High Resolution Imaging System (Visualsonics, Toronto, Canada). Mice were lightly anesthetised with 2.5\% 2-2-2-tribromoethanol (avertin, $0.01 \mathrm{ml} / \mathrm{g}$ i.p.) and were allowed to breathe spontaneously. LV enddiastolic (LVEDD) and end-systolic (LVESD) dimensions were measured from original tracings by using the leading edge convention of the American Society of Echocardiography. LV percent fractional shortening (FS) and LV mass (LVM) were calculated as previously described [29].

Quantitative mRNA measurement in the mouse myocardium

DNA-free total RNA was extracted from myocardial samples by a standard protocol with the RNeasy kit and RNase-free DNAse Set (Qiagen, Hilden, Germany). Firststrand cDNA synthesis was carried out with iScript cDNA synthesis kit (BioRad, München, Germany) according to manufacturer's instructions. Real-time polymerase chain reactions (PCRs) were performed on a Biorad iQ-Cycler in a volume of $20 \mu \mathrm{L}$ in a 96-well plate. The reaction mixture consisted of $1 \mu \mathrm{l}$ cDNA with $19 \mu \mathrm{l}$ SYBR GRN SUPERMIX (BioRad, München, Germany). After initial denaturation for $60 \mathrm{~s}$ at $95^{\circ} \mathrm{C}$, the cycling programme consisted of 40 cycles of $95^{\circ} \mathrm{C}$ for $15 \mathrm{~s}, 60^{\circ} \mathrm{C}$ for $10 \mathrm{~s}$ and $72^{\circ} \mathrm{C}$ for $15 \mathrm{~s}$. Emission at $530 \mathrm{~nm}$ was measured at the end of each cycle. Primer sequences used were: GAPDH sense: GC AGTGGCAAAGTGGAGATT, antisense: TCTCCATGG TGGTGAAGACA; ANP sense: TGATAGATGAAGGCA GGAAGCCGC, antisense: AGGATTGGAGCCCAGAGT GGACTAGG; BNP sense: TCTCCAGAGCAATTCAAG AT, antisense: AACAACTTCAGTGCGTTACA; SERCA sense: AGATGGTCCTGGCAGATGAC, antisense: GTCC AGGTCTGGAGGATTGA; MCIP sense ACTGGAAGG TGGTGTCCTTGTC, antisense: TCCAGCTTGGGCTT GACTGAG. cDNAs with known concentrations were used to generate quantification standard curves. Expression data were normalised to GAPDH.

Luciferase enzymatic assay

Luciferase enzymatic activity in the tissue extracts was measured by a commercial kit (luciferase reporter gene assay, high sensitivity, Roche, Mannheim, Germany) according to the manufacturer's indications. The light intensity was measured with a luminometer (Mithras LB 940, Berthold Technologies, Bad Wildbad, Germany) and expressed as relative light units (RLU) over micrograms of protein. 
Measurement of proANP and BNP in serum and cGMP in the myocardium

The BNP (BioSupply UK, Bradford, UK) and proANP (Biomedica, Wien, Austria) were measured in serum of the mice collected by excision of the heart. cGMP was measured by ELISA in homogenated left ventricular tissue (GE Healthcare, Chalfont St. Giles, UK). The ELISAs were done according to the manufacturer's instructions.

Western immunoblot analysis

Frozen muscle strips or pieces of the left ventricle were thawed on ice in $50 \mu \mathrm{L}$ of homogenisation buffer and homogenised. Protein concentrations of the suspensions were determined, and $20 \mu \mathrm{g}$ of samples subjected to SDSPAGE. Western blotting was carried out according to standard protocols, using antibodies against SERCA (ABR, Rockford, USA) PLB (Badrilla, Leeds, UK), phosophoPLB (Badrilla, Leeds, UK) and GAPDH (BioTrend, Cologne, Germany). For quantification, an enhanced chemoluminescence detection system (Amersham) was used according to the manufacturer's instructions.

Calculation and statistical analysis

Gene- and protein-expression was analysed using two-wayANOVA or unpaired Student's $t$ test with values of $p<0.05$ considered statistically significant. Numbers of experiments are indicated in the figure legend in the following order: Sham/TAC or WT-Sham/-WT-TAC/KOSham/KO-TAC.

\section{Results}

Load-dependent regulation of SERCA

SERCA-mRNA expression is upregulated in vivo after $6 \mathrm{~h}$ by $32 \%$ in TAC $(p<0.05$; Fig. 1$)$. After $24 \mathrm{~h}$, the expression of SERCA has returned to the sham level (Fig. 1).

Load-specific regulation of natriuretic peptides

Six hours after TAC, the serum level of ANP $(+182 \%$; Fig. 2a), but not BNP (Fig. 2b), was significantly increased compared to control. Serum levels of BNP and pro ANP were elevated $24 \mathrm{~h}$ after TAC (proANP: $+60 \%, p<0.05$; BNP: $+274 \%, p<0.01$; Fig. $2 \mathrm{c}, \mathrm{d})$. The main source of ANP and BNP $24 \mathrm{~h}$ after TAC is the left ventricle (BNP $+507 \% p<0.05$; Fig. 3a). The expression of BNP was paralleled by ANP, only with lower amplitude (Fig. 3b).

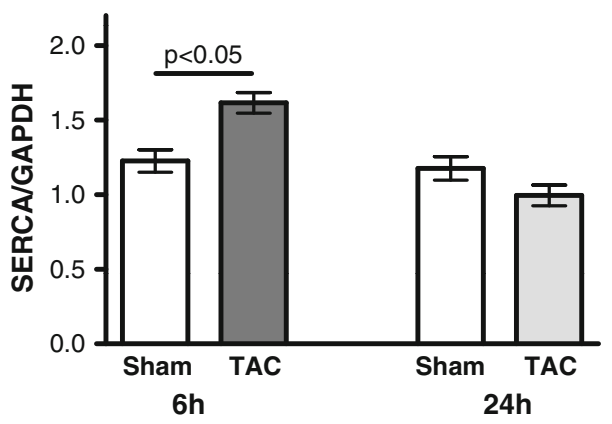

Fig. 1 Regulation of SERCA expression following TAC. mRNA expression of SERCA $6 \mathrm{~h}(n=6 / 6)$ and $24 \mathrm{~h}(n=6 / 6)$ after the intervention. TAC increased SERCA expression by $32 \%$ after $6 \mathrm{~h}$

Regulation of the cGMP level by load

Six hours after TAC, the cGMP level showed only a tendency to be increased, but $24 \mathrm{~h}$ after TAC a clear increase in cGMP could be shown $(+307 \%$; Fig. 4 a).

Influence of the particulate guanylyl cyclase on SERCA regulation

We tested the hypothesis that BNP would depress loaddependent SERCA upregulation at time periods longer than $6 \mathrm{~h}$ following surgery. For this purpose, we used genetically modified animals lacking the guanylyl cyclase-A (GC-A, BNP receptor) in cardiomyocytes. Indeed, in those animals, SERCA upregulation was still preserved $24 \mathrm{~h}$ following TAC (Fig. 4b). This hypothesis is further supported by the finding that application of BNP via osmotic mini pumps prevented SERCA-mRNA upregulation $6 \mathrm{~h}$ after TAC (Fig. 4c).

The SERCA regulation by load and its BNP-dependent depression was detectable at the protein level as well. $24 \mathrm{~h}$ after TAC, protein levels of SERCA were significantly higher in GC-A-KO compared to WT animals. Conversely $6 \mathrm{~h}$ after TAC, protein levels of SERCA were significantly lower in animals with continuous infusion of BNP (Fig. 5a, b). Phospholamban (PLB) expression was not changed after 6 and 24 h (Fig. 5a, c), and phosphorylation of PLB was increased after $24 \mathrm{~h}$ in both WT and GC-A-KO animals after TAC to a comparable degree (Fig. 5a, d).

Analysis of in vivo contractile function

in the GC-A-KO animals

We previously could show that increased SERCA expression in our in vitro model leads to an improved forcefrequency relationship [17]. Here, we studied the contractile function in the pressure-overloaded GC-A-KO and control mice $24 \mathrm{~h}$ after TAC. No decrease in fractional shortening (FS) could be seen in WT-TAC compared to control 
Fig. 2 Serum levels of natriuretic peptides. a, b Serum levels of proANP (a) and BNP (b) after $6 \mathrm{~h}$ after TAC $(n=6 / 6)$; $\mathbf{c}$, d serum level of proANP (c) and BNP (d) $24 \mathrm{~h}$ after TAC $(n=6 / 6)$
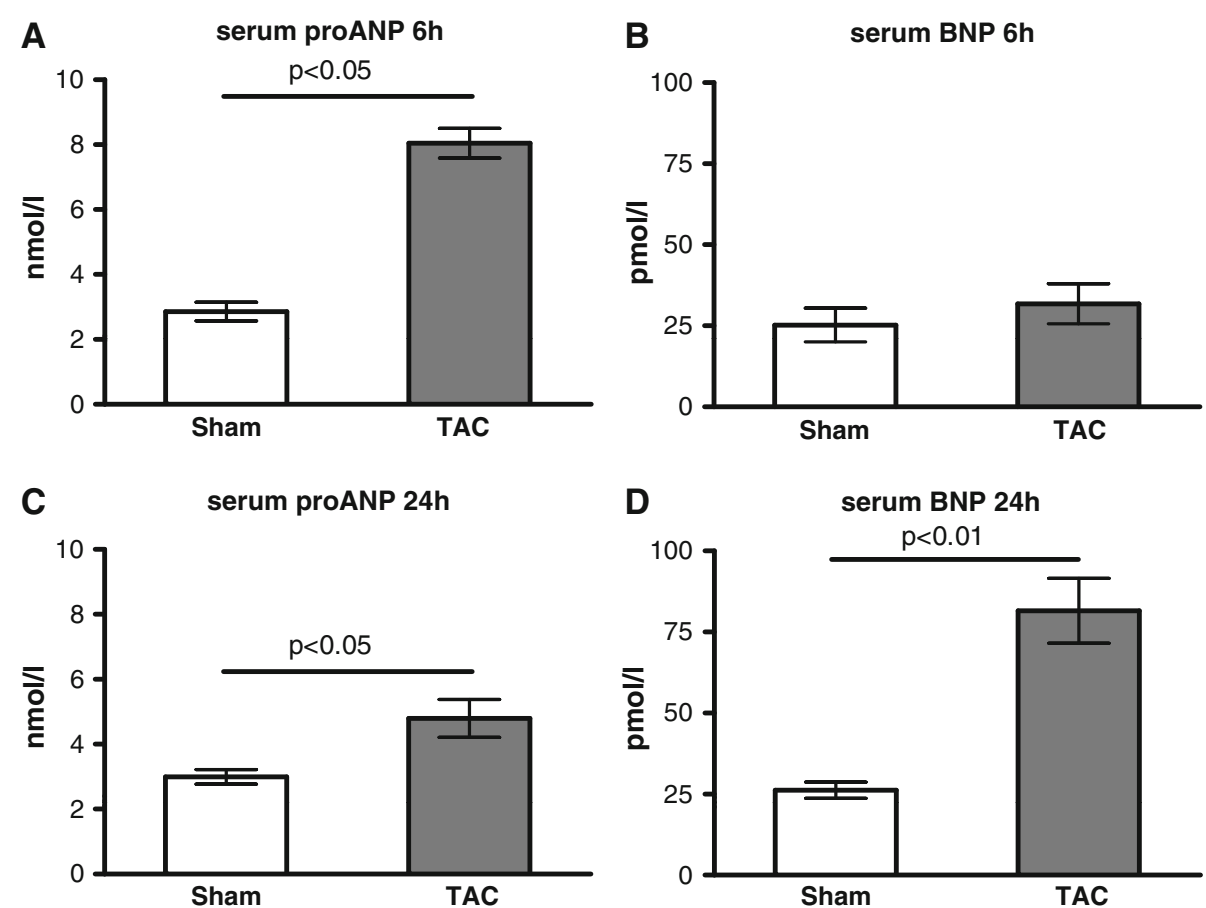
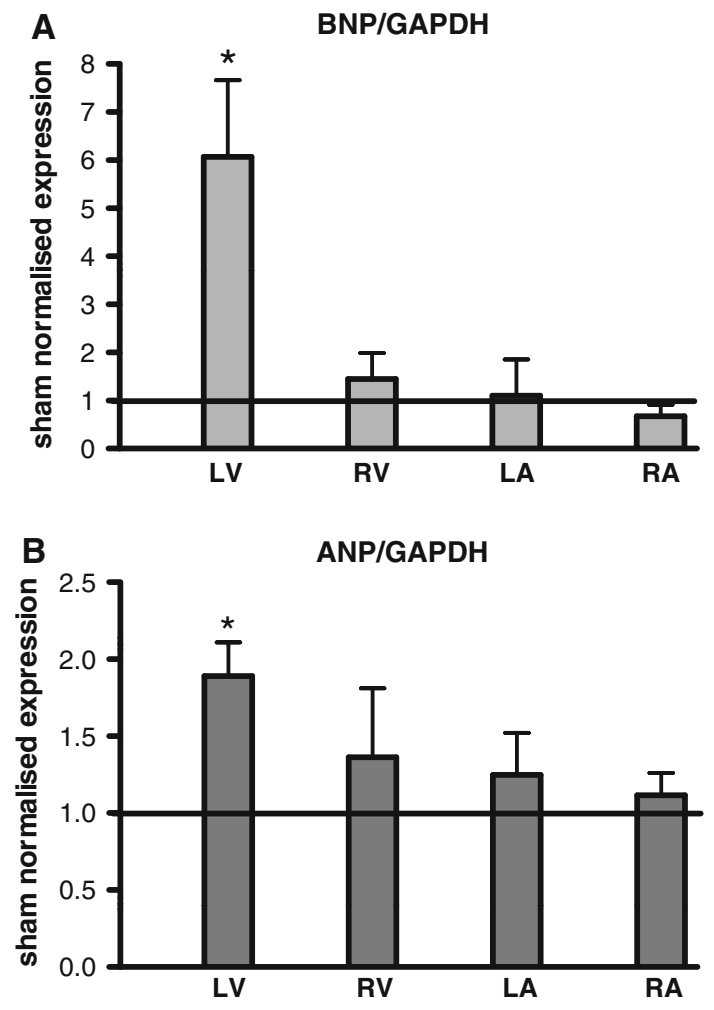

Fig. 3 Source of the natriuretic peptides: expression of BNP (a) and ANP (b) following TAC normalised to sham in the left $(L V)$ and right $(R V)$ ventricle and the left $(L A)$ and the right $(R A)$ atrium $24 \mathrm{~h}$ after intervention (per chamber: $n=6 / 6$ ); ${ }^{*} p<0.05$ TAC versus Sham

(Fig. 6a-c), indicating a still good contractile function in the pressure-overloaded heart. Also the GC-A-KO-TAC animals showed a similar FS compared to WT-TAC.
Regulation of SERCA via NFAT

Evidence from in vitro studies from us and other groups suggest that SERCA regulation may occur via calcineurinNFAT (CN) activation [1, 17]. We measured NFATluciferase activity and MCIP expression as parameters of calcineurin activation in vivo. Both MCIP expression and NFAT-luciferase activity were elevated in the TAC model after $6 \mathrm{~h}$ indicating $\mathrm{CN}$ activation. After $24 \mathrm{~h}$, MCIP expression and NFAT-luciferase activity returned to normal (Fig. 7a, b). Again, MCIP expression was regulated in parallel to SERCA expression in the GC-A-KO animals and in mice with BNP infusion. MCIP expression after TAC was still increased in GC-A-KO mice after $24 \mathrm{~h}$ (TAC-WT vs. TAC-KO $+106 \%, p<0.05$; Fig. 7c) and reduced in mice with BNP infusion after $6 \mathrm{~h}$ (TAC saline vs. TAC BNP $-62 \%, p<0.05$; Fig. 7d). This shows that calcineurin activation occurs in parallel to SERCA regulation at an early timepoint, suggesting an important role of calcineurin for SERCA upregulation under in vivo conditions.

Load-dependent regulation of SERCA and BNP expression in MLP-KO mice

The load-dependent regulation of SERCA and BNP was analysed in the MLP-KO-mouse heart failure model. At the age of 12 weeks, when the TAC procedure was performed, there was a clear upregulation of $\operatorname{BNP}(p<0.01)$ and a downregulation of SERCA $(-37 \%, p<0.01)$ in the MLP$\mathrm{KO}$ compared to the wild-type mice. 

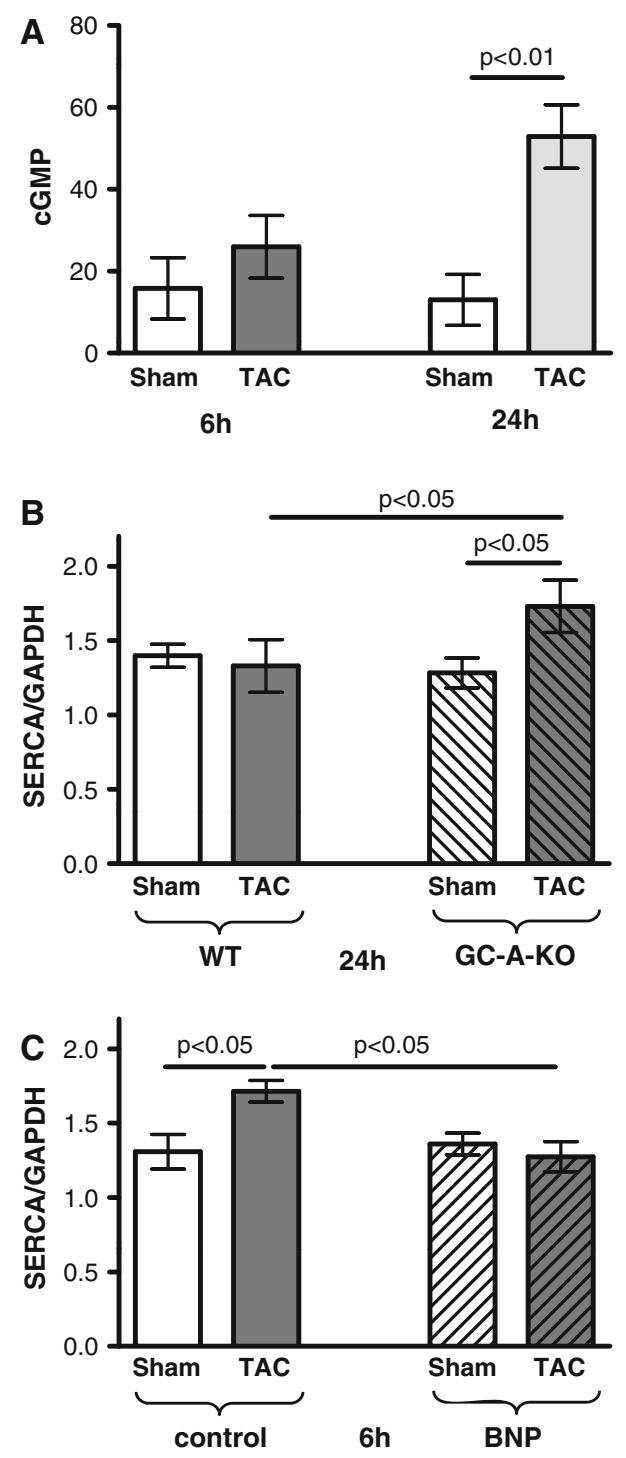

Fig. 4 Inhibition of load-dependent SERCA-mRNA upregulation by the BNP-GC-A signal pathway. a Myocardial cGMP level 6 and $24 \mathrm{~h}$ after TAC $(n=6 / 6 / 6 / 6)$. b SERCA-mRNA expression $24 \mathrm{~h}$ after TAC in WT and GC-A-KO mice $(n=8 / 11 / 10 / 14)$. SERCA is increased by $35 \%$ in KO versus WT mice after TAC. $\mathbf{c}$ Inhibition of afterload-dependent SERCA-mRNA upregulation after $6 \mathrm{~h}$ by BNP infusion $(n=6 / 7 / 6 / 8)$. Following TAC, SERCA was $26 \%$ lower in mice with BNP application compared to control

The TAC induced an upregulation of BNP in wild type $(+506 \%, p<0.05)$ and MLP-KO $(+325 \%, p<0.01$; Fig. 8a). The SERCA upregulation after $6 \mathrm{~h}$ was only demonstrable in the wild type $(+34 \%, p<0.05)$, but not in the MLP-KO mice (Fig. 8b).

\section{Discussion}

The present data show that acute hemodynamic load following aortic constriction results in transient upregulation of SERCA. SERCA upregulation is associated with MCIP expression indicating increased calcineurin $(\mathrm{CN})$ activity. Subsequent decrease of SERCA expression is due to increased expression of ANP and BNP and subsequent activation of the guanylyl cyclase receptor. We conclude that load immediately upregulates SERCA mediated by $\mathrm{CN}$ activation and that subsequent BNP expression results in downregulation of SERCA through cGMP-dependent inhibition of $\mathrm{CN}$. The present in vivo data are consistent with previous in vitro studies and support the hypothesis that BNP may be involved in the downregulation of SERCA as it occurs with persistent increase in hemodynamic load.

Mechanisms of SERCA upregulation and hemodynamic relevance

The SERCA upregulation was correlated with MCIP expression and with increased NFAT-luciferase activity. We did not show a direct proof for regulation of SERCA via NFAT in vivo, but previously we [17] and others [1] could show that calcineurin-NFAT is involved in SERCA upregulation. Calcineurin transgenic mice show an increased SERCA protein expression [5]. In vitro experiments in cells transfected with different SERCApromoter-luciferase constructs showed that NFAT in combination with MEF2 induced an upregulation of the luciferase activity in long promoter constructs $(6.6 \mathrm{~kb})$ [35]. Here, we found that NFAT activity is increased in parallel with SERCA regulation at short time intervals $(6 \mathrm{~h})$ and may therefore be important for an adaptive hypertrophic response. The concept of an early beneficial effect of calcineurin is also supported by the fact that a load-dependent increase in proteins involved in energy metabolism occurs through calcineurin [30]. Favourable effects of calcineurin activation are also reported from calcineurin-Aß-knockout mice which show apoptosis and a worse prognosis after myocardial infarction [3]. In contrast to short-term $\mathrm{CN}$ effects, long-term activation is considered harmful [25].

\section{Beneficial and unfavourable effects of BNP}

Experimental findings from transgenic animals implicate that the BNP-GC-A-cGMP signal pathway mediates beneficial effects on the heart. BNP has antihypertrophic and antifibrotic effects [19]. In addition, it has also been shown that BNP stimulates angiogenesis in the pressure-overloaded heart [20]. Activation of PKG by BNP via GC-A [9] has also cardioprotective effects by influencing mitochondrial pore opening [13, 14]. Loss of the GC-A receptor in the heart increases the susceptibility to heart failure in $\mathrm{PO}$ $[15,26,27,34]$. From this point of view, one may speculate 
Fig. 5 Regulation of SERCA and PLB-protein expression by BNP. a Example of SERCA, PLB western blots; b SERCAprotein expression in sham and TAC animals with BNP infusion after $6 \mathrm{~h}$ and in GC-A$\mathrm{KO}$ animals after $24 \mathrm{~h}(n=7$ per group). SERCA is reduced by $17 \%$ after $6 \mathrm{~h}$ in TAC animals with BNP infusion compared to control while it is $25 \%$ higher after $24 \mathrm{~h}$ in TAC animals with GC-A-KO compared to WT. c Expression of PLB in sham and TAC animals with BNP infusion after $6 \mathrm{~h}$ and in GC-A-KO animals after $24 \mathrm{~h}$ ( $n=6$ per group); d phosphorylation of PLB in sham and TAC animals with BNP infusion after $6 \mathrm{~h}$ and in GC-A-KO animals after $24 \mathrm{~h}$ ( $n=6$ per group)

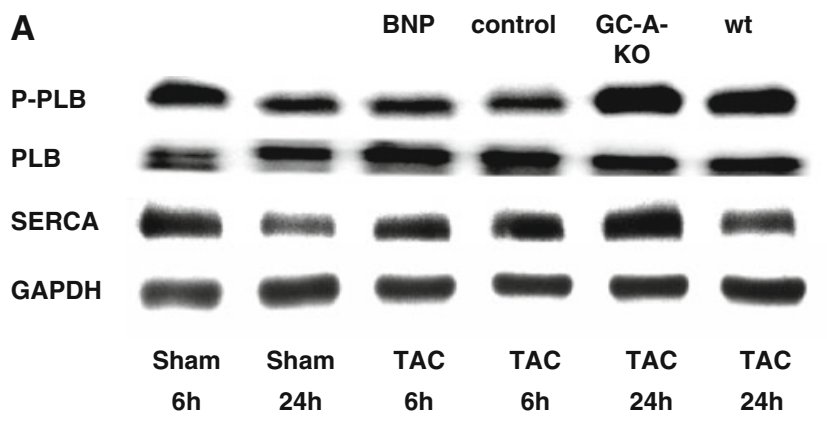

B

Protein expression
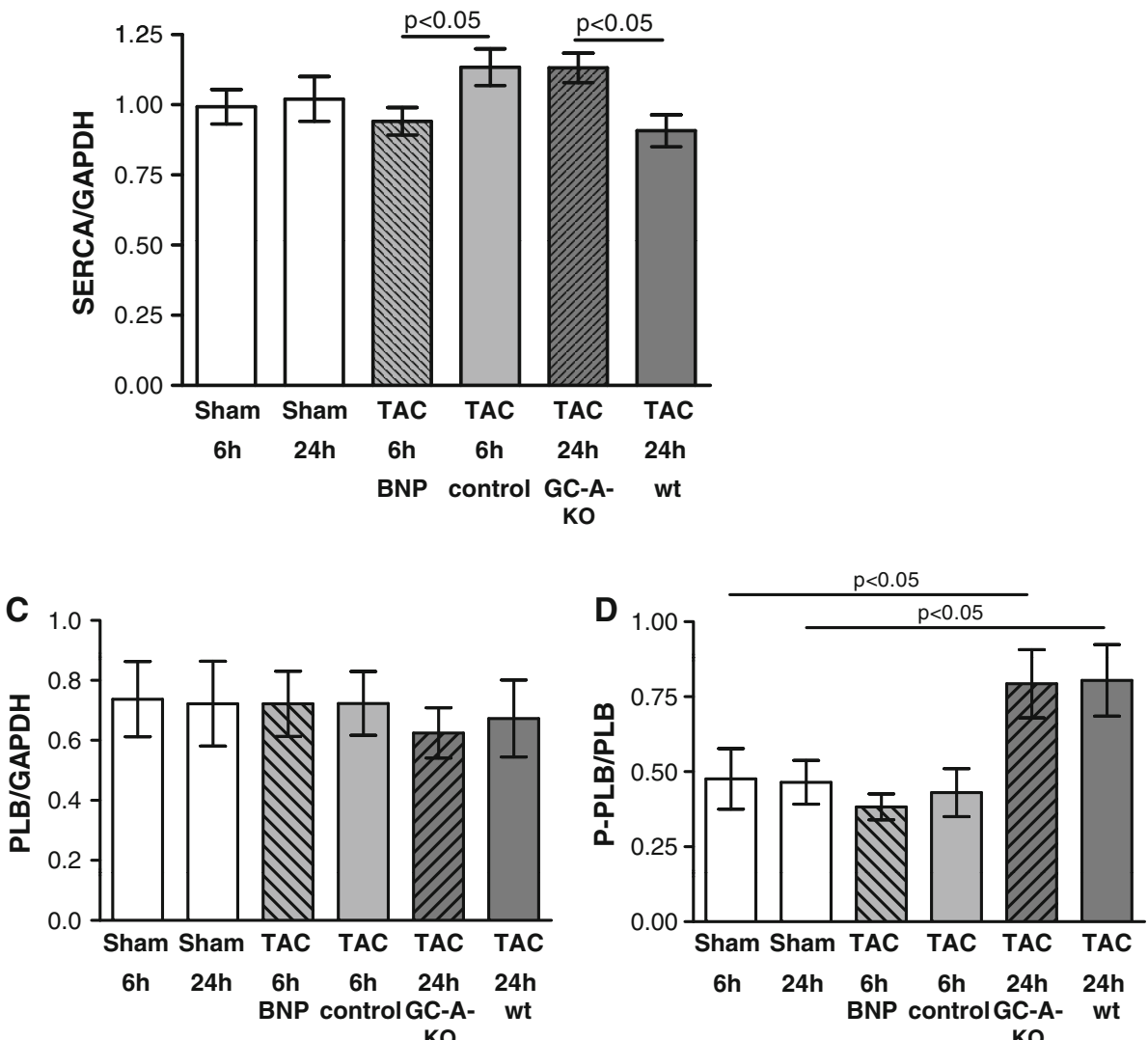

KO that teleologically BNP may have a protective role on loadinduced hypertrophy. Along the same direction, downregulation of SERCA may be beneficial reducing energy consumption for excitation-contraction coupling and myofilament activation. This, however, would occur at the price of reduced contractility. Here, we show that BNP has a negative effect on SERCA regulation in vivo. This is consistent with our previous in vitro results [17] and with Sodi et al. [32]. They also found that in isolated rat cells BNP treatment reduced SERCA expression. We could show that in heart failure patients treated with a left ventricular assist device (LVAD), SERCA was only upregulated in the subgroup of patients in whom BNP-expression was reduced by this therapy. In the subgroup with sustained
BNP elevation, SERCA expression was not changed [17]. The effect of BNP on SERCA expression may be also relevant when BNP (Nesiritide) is used to treat heart failure in patients. Nesiritide is used to treat acute decompensated heart failure. Of note, a meta-analysis of Sackner-Bernstein et al. [28] showed an increased mortality in patients treated with Nesiritide; however, mortality was not increased in other studies with short Nesiritide application [7]. Prolonged treatment of Nesiritide has not been studied so far.

\section{Differences between ANP and BNP}

Both natriuretic peptides activate the same guanylyl receptor (GC-A) and lead to an increase in cGMP. Here, 


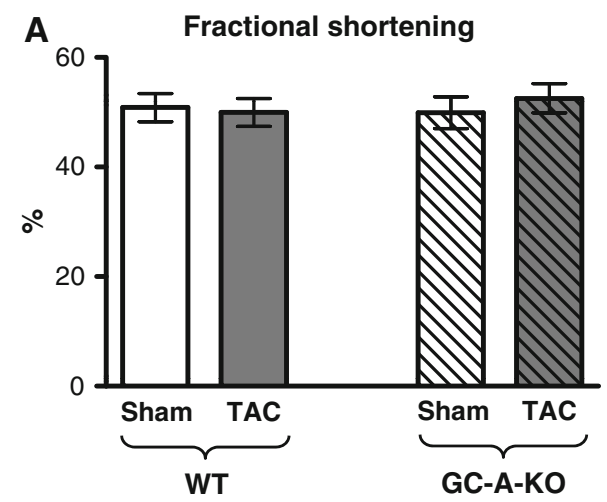

B
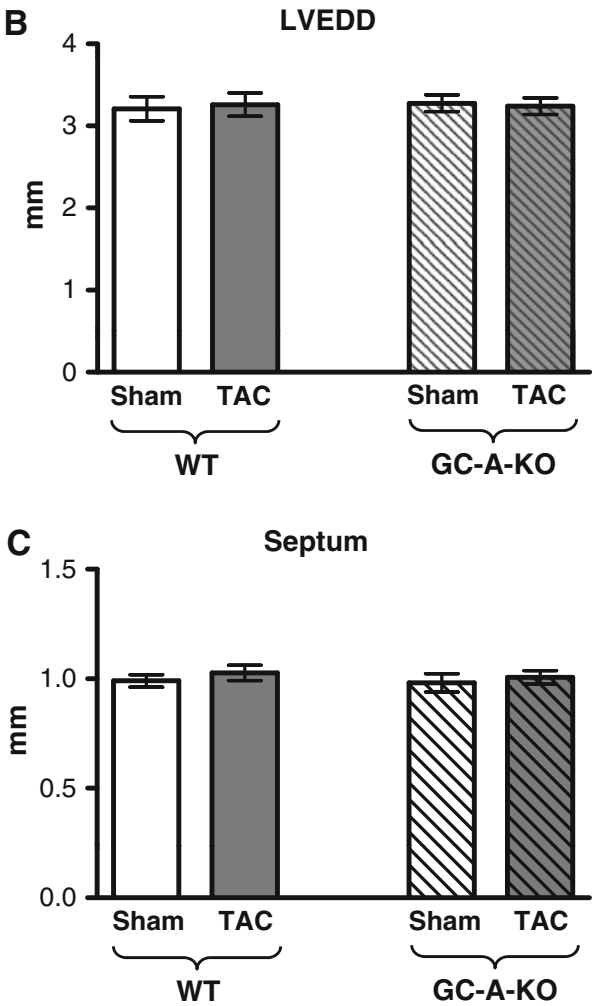

Fig. 6 Myocardial function of GC-A-KO animals and WT controls $24 \mathrm{~h}$ after TAC $(n=6 / 6 / 6 / 6)$. a Fractional shortening; b left ventricular enddiastolic diameter; $\mathbf{c}$ septum width

we could show that after $24 \mathrm{~h}$ an increase in ANP and BNP inhibited the load-induced SERCA upregulation. The increase of the natriuretic peptides after $24 \mathrm{~h}$ might mostly be due to ventricular synthesis of BNP and ANP. Other groups could show that stretch leads to an increased BNP promoter activation after $30 \mathrm{~min}$ [12] and an upregulation of BNP mRNA expression in vitro already after $6 \mathrm{~h}$ in the culture medium of isolated stretched cells [22]. We analysed the in vivo expression of ANP and BNP in the serum by a non-radioactive ELISA. Using a radioimmunoassay might have a higher sensitivity, and therefore, an increase in BNP might be detected earlier. Also the experiments were done in vitro, while we measured the concentration in the blood in vivo. The BNP synthesis in the cardiomyocytes takes a certain time during which the inhibitory action of BNP via GC-A is not present in the heart. At later timepoints $(24 \mathrm{~h}$ and later), enough BNP is produced to induce the known BNP effects.

The ANP seems to have another role for the cardiovascular system. Here, we could show that proANP expression in the blood was increased after $6 \mathrm{~h}$, but this did not lead to an increase in myocardial cGMP and an inhibition of SERCA upregulation by load. This indicates that serum ANP might predominantly have extracardiac functions. The increase in ANP $6 \mathrm{~h}$ after load might be explained by the release of stored ANP in the granula of the atrial myocytes [6]. Reason for the lack of systemic ANP on myocardial SERCA regulation could be the higher degradation of ANP in the heart. The neutral endopeptidase (NEP) and also the natriuretic peptide clearance receptor (GC-C) have a higher affinity to ANP, and therefore, systemic ANP might be faster degraded $[31,36]$. So, the function of ANP might be more focused on renal and vascular actions of the natriuretic peptides, whereas BNP seems to have mostly local myocardial functions [18].

\section{Mechanism of BNP-mediated SERCA downregulation}

Activation of PKG by BNP via GC-A leading to cGMP elevation is an important signal pathway of the natriuretic peptides [32]. Our data support the notion that GC-A is involved in suppression of SERCA expression by BNP. As shown recently, the regulation of SERCA by BNP involves cGMP and activation of PKG [17] and PKG can inhibit calcineurin activation [8]. This is consistent with our data suggesting relevance of $\mathrm{CN}$ in load-dependent SERCA regulation. We suggest that $\mathrm{BNP}$ inhibits $\mathrm{CN}$ activation and thereby suppresses the load-dependent $\mathrm{CN}$-mediated upregulation of SERCA. The inhibitory action of BNP on $\mathrm{CN}$ activation is probably induced by a PKG-induced reduction of $\mathrm{Ca}^{2+}$ transients $[24,39]$.

\section{Conclusion}

The SERCA is regulated by load in vivo. The upregulation of SERCA occurs via an activation of the calcineurinNFAT pathway and is inhibited by BNP acting via the GCA receptor. Therefore, short activation of calcineurin may be beneficial for adaptation to acute increases in hemodynamic load. 
Fig. 7 Participation of calcineurin-NFAT signalling in SERCA regulation $6(n=6 / 6)$ and $24(n=6 / 6)$ hours after TAC; a MCIP expression; b NFAT-luciferase activity; c, $\mathbf{d}$ comparison of MCIP expression in the GC-A-KO versus sham (c, $n=11 / 14)$ and the BNP infusion versus sham mice $(\mathbf{d}, n=7 / 8)$. MCIP is increased by $106 \%$ after $24 \mathrm{~h}$ of TAC in GC-A-KO animals compared to WT. MCIP is reduced by $62 \%$ after $6 \mathrm{~h}$ of TAC in animals with BNP infusion compared to control
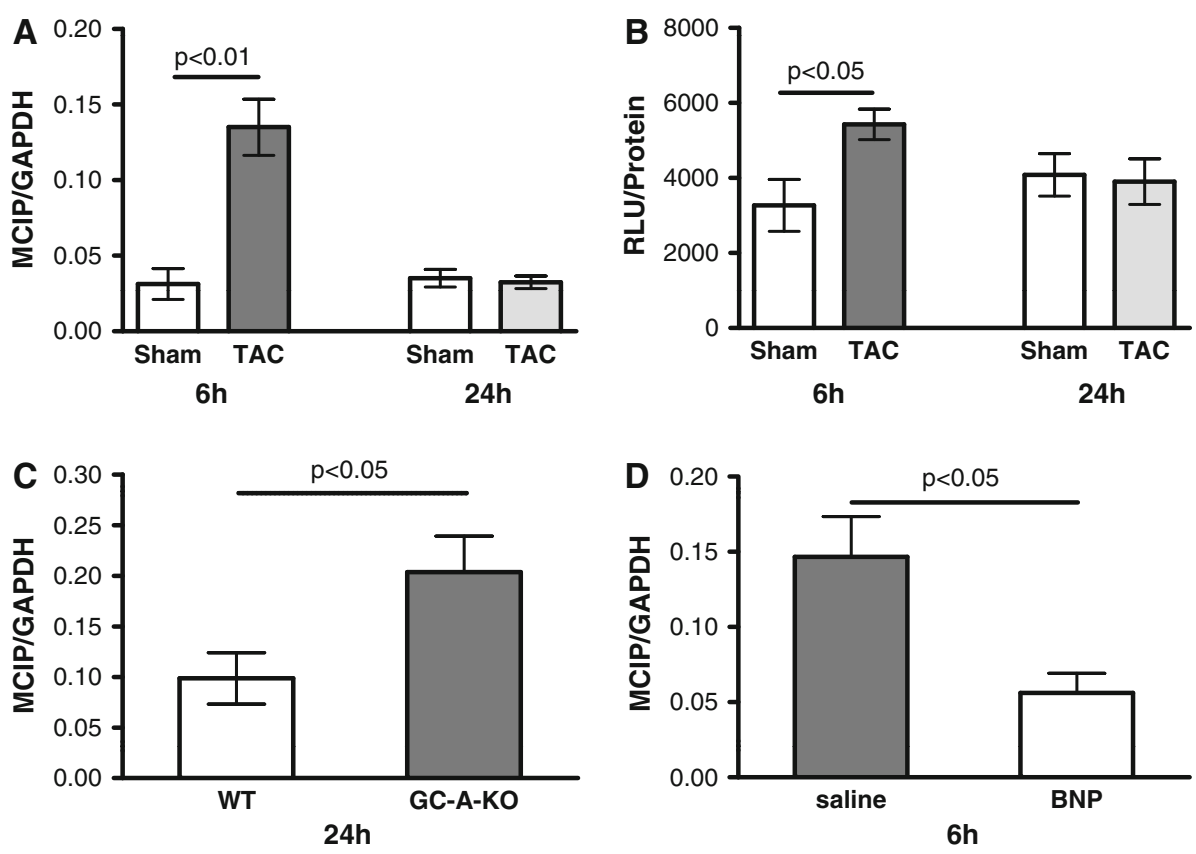
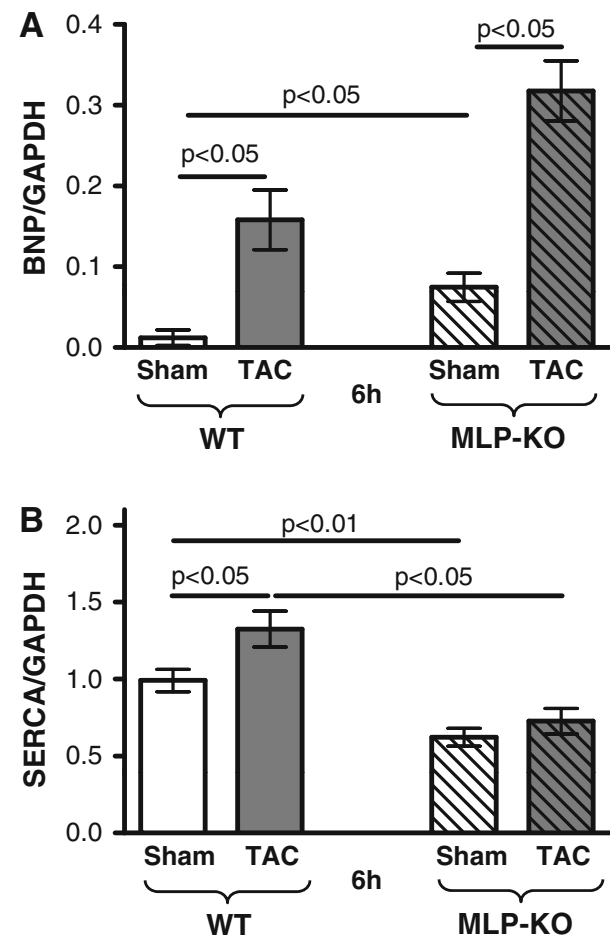

Fig. 8 Regulation of SERCA expression in the MLP-knockout heart failure model: BNP (a) and SERCA expression (b) $6 \mathrm{~h}$ after TAC in WT and MLP-KO animals $(n=7 / 6 / 6 / 7)$. BNP is significantly upregulated after TAC in both WT and MLP-KO animals. SERCA upregulation after TAC occurs in WT, but not in MLP-KO animals

Acknowledgments We are grateful to Brigitte Korff and Anika Hunold for excellent technical assistance. This work was supported by the Deutsche Forschungsgemeinschaft (grant KFO 155 TP1 (KO 1872/2-1 to G.H. and H.K.) and EUGeneHeart (project number LSHM-CT-2005-018833).
Conflict of interest The authors declare that they have no conflict of interest.

Open Access This article is distributed under the terms of the Creative Commons Attribution Noncommercial License which permits any noncommercial use, distribution, and reproduction in any medium, provided the original author(s) and source are credited.

\section{References}

1. Anwar A, Taimor G, Korkususz H, Schreckenberg R, Berndt T, Abdallah Y, Piper HM, Schlüter KD (2005) PKC-independent signal transduction pathways increase SERCA2 expression in adult rat cardiomyocytes. J Mol Cell Cardiol 39:911-919

2. Arber S, Hunter JJ, Ross J Jr, Hongo M, Sansig G, Borg J, Perriard JC, Chien KR, Caroni P (1997) MLP-deficient mice exhibit a disruption of cardiac cytoarchitectural organization, dilated cardiomyopathy, and heart failure. Cell 88: 393-403

3. Bueno OF, Lips DJ, Kaiser RA, Wilkins BJ, Dai YS, Glascock BJ, Klevitsky R, Hewett TE, Kimball TR, Aronow BJ, Doevendans PA, Molkentin JD (2004) Calcineurin Abeta gene targeting predisposes the myocardium to acute ischemia-induced apoptosis and dysfunction. Circ Res 94:91-99

4. Chien KR, Zhu H, Knowlton KU, Miller-Hance W, van-Bilsen M, O'Brien TX, Evans SM (1993) Transcriptional regulation during cardiac growth and development. Annu Rev Physiol 55:77-95

5. Chu G, Carr AN, Young KB, Lester JW, Yatani A, Sanbe A, Colbert MC, Schwartz SM, Frank KF, Lampe PD, Robbins J, Molkentin JD, Kranias EG (2002) Enhanced myocyte contractility and $\mathrm{Ca}^{2+}$ handling in a calcineurin transgenic model of heart failure. Cardiovasc Res 54:105-116

6. de Bold AJ, Ma KK, Zhang Y, de Bold ML, Bensimon M, Khoshbaten A (2001) The physiological and pathophysiological modulation of the endocrine function of the heart. Can J Physiol Pharmacol 79:705-714 
7. Dontas ID, Xanthos T, Dontas I, Lelovas P, Papadimitriou L (2009) Impact of nesiritide on renal function and mortality in patients suffering from heart failure. Cardiovasc Drugs Ther 23:221-233

8. Fiedler B, Lohmann SM, Smolenski A, Linnemuller S, Pieske B, Schroder F, Molkentin JD, Drexler H, Wollert KC (2002) Inhibition of calcineurin-NFAT hypertrophy signaling by cGMPdependent protein kinase type I in cardiac myocytes. Proc Natl Acad Sci USA 99:11363-11368

9. Gorbe A, Giricz Z, Szunyog A, Csont T, Burley DS, Baxter GF, Ferdinandy P (2010) Role of cGMP PKG signaling in the protection of neonatal rat cardiac myocytes subjected to simulated ischemia/reoxygenation. Basic Res Cardiol 105(5): 643-650

10. Hasenfuss G, Reinecke H, Studer R, Meyer M, Pieske B, Holtz J, Holubarsch C, Posival H, Just H, Drexler H (1994) Relation between myocardial function and expression of sarcoplasmic reticulum $\mathrm{Ca}^{2+}$-ATPase in failing and nonfailing human myocardium. Circ Res 75:434-442

11. Hasenfuss G, Meyer M, Schillinger W, Preuss M, Pieske B, Just $\mathrm{H}$ (1997) Calcium handling proteins in the failing human heart. Basic Res Cardiol 92(Suppl 1):87-93

12. Hautala N, Tenhunen O, Szokodi I, Ruskoaho H (2002) Direct left ventricular wall stretch activates GATA4 binding in perfused rat heart: involvement of autocrine/paracrine pathways. Pflugers Arch 443:362-369

13. Heusch G, Boengler K, Schulz R (2008) Cardioprotection: nitric oxide, protein kinases, and mitochondria. Circulation 118:19151919

14. Heusch G, Boengler K, Schulz R (2010) Inhibition of mitochondrial permeability transition pore opening: the holy grail of cardioprotection. Basic Res Cardiol 105:151-154

15. Holtwick R, van Eickels M, Skryabin BV, Baba HA, Bubikat A, Begrow F, Schneider MD, Garbers DL, Kuhn M (2003) Pressureindependent cardiac hypertrophy in mice with cardiomyocyterestricted inactivation of the atrial natriuretic peptide receptor guanylyl cyclase-A. J Clin Invest 111:1399-1407

16. Hu P, Zhang D, Swenson L, Chakrabarti G, Abel ED, Litwin SE (2003) Minimally invasive aortic banding in mice: effects of altered cardiomyocyte insulin signaling during pressure overload. Am J Physiol Heart Circ Physiol 285:H1261H1269

17. Kögler H, Schott $P$, Toischer $K$, Milting $H$, Nguyen van $P$, Kohlhaas M, Grebe C, Kassner A, Domeier E, Teucher N, Seidler T, Knöll R, Maier LS, El-Banayosy A, Körfer R, Hasenfuss G (2006) Relevance of brain natriuretic peptide in preload-dependent regulation of cardiac sarcoplasmic reticulum $\mathrm{Ca}^{2+}$ ATPase expression. Circulation 113:2724-2732

18. Kuhn M (2004) Molecular physiology of natriuretic peptide signalling. Basic Res Cardiol 99:76-82

19. Kuhn M (2003) Structure, regulation, and function of mammalian membrane guanylyl cyclase receptors, with a focus on guanylyl cyclase-A. Circ Res 93:700-709

20. Kuhn M, Völker K, Schwarz K, Carbajo-Lozoya J, Flögel U, Jacoby C, Stypmann J, van Eickels M, Gambaryan S, Hartmann M, Werner M, Wieland T, Schrader J, Baba HA (2009) The natriuretic peptide/guanylyl cyclase - a system functions as a stress-responsive regulator of angiogenesis in mice. J Clin Invest 119:2019-2030

21. Lee DI, Vahebi S, Tocchetti CG, Barouch LA, Solaro RJ, Takimoto E, Kass DA (2010) PDE5A suppression of acute betaadrenergic activation requires modulation of myocyte beta-3 signaling coupled to PKG-mediated troponin I phosphorylation. Basic Res Cardiol 105:337-347
22. Liang F, Wu J, Garami M, Gardner DG (1997) Mechanical strain increases expression of the brain natriuretic peptide gene in rat cardiac myocytes. J Biol Chem 272:28050-28056

23. Maack C, O'Rourke B (2007) Excitation-contraction coupling and mitochondrial energetics. Basic Res Cardiol 102(5):369-392

24. Mery PF, Lohmann SM, Walter U, Fischmeister R (1991) $\mathrm{Ca}^{2+}$ current is regulated by cyclic GMP-dependent protein kinase in mammalian cardiac myocytes. Proc Natl Acad Sci USA 88:1197-1201

25. Molkentin JD, Lu JR, Antos CL, Markham B, Richardson J, Robbins J, Grant SR, Olson EN (1998) A calcineurin-dependent transcriptional pathway for cardiac hypertrophy. Cell 93:215-228

26. Nishikimi T, Hagaman JR, Takahashi N, Kim HS, Matsuoka H, Smithies O, Maeda N (2005) Increased susceptibility to heart failure in response to volume overload in mice lacking natriuretic peptide receptor-A gene. Cardiovasc Res 66:94-103

27. Patel JB, Valencik ML, Pritchett AM, Burnett JC Jr, McDonald JA, Redfield MM (2005) Cardiac-specific attenuation of natriuretic peptide A receptor activity accentuates adverse cardiac remodeling and mortality in response to pressure overload. Am J Physiol Heart Circ Physiol 289:H777-H784

28. Sackner-Bernstein JD, Kowalski M, Fox M, Aaronson K (2005) Short-term risk of death after treatment with nesiritide for decompensated heart failure: a pooled analysis of randomized controlled trials. JAMA 293:1900-1905

29. Schmidt AG, Kadambi VJ, Ball N, Sato Y, Walsh RA, Kranias EG, Hoit BD (2000) Cardiac-specific overexpression of calsequestrin results in left ventricular hypertrophy, depressed forcefrequency relation and pulsus alternans in vivo. $\mathrm{J}$ Mol Cell Cardiol 32:1735-1744

30. Schott P, Asif AR, Gräf C, Toischer K, Hasenfuss G, Kögler H (2008) Myocardial adaptation of energy metabolism to elevated preload depends on calcineurin activity: a proteomic approach. Basic Res Cardiol 103:232-243

31. Smith MW, Espiner EA, Yandle TG, Charles CJ, Richards AM (2000) Delayed metabolism of human brain natriuretic peptide reflects resistance to neutral endopeptidase. J Endocrinol 167:239-246

32. Sodi R, Dubuis E, Shenkin A, Hart G (2008) B-type natriuretic peptide (BNP) attenuates the L-type calcium current and regulates ventricular myocyte function. Regul Pept 151:95-105

33. Toischer K, Lehnart SE, Tenderich G, Milting H, Körfer R, Schmitto JD, Schöndube FA, Kaneko N, Loughrey CM, Smith GL, Hasenfuss G, Seidler T (2010) K201 improves aspects of the contractile performance of human failing myocardium via reduction in $\mathrm{Ca}^{2+}$ leak from the sarcoplasmic reticulum. Basic Res Cardiol 105:279-287

34. Tokudome T, Horio T, Kishimoto I, Soeki T, Mori K, Kawano Y, Kohno M, Garbers DL, Nakao K, Kangawa K (2005) Calcineurin-nuclear factor of activated $\mathrm{T}$ cells pathway-dependent cardiac remodeling in mice deficient in guanylyl cyclase A, a receptor for atrial and brain natriuretic peptides. Circulation 111:3095-3104

35. Vlasblom R, Muller A, Musters RJ, Zuidwijk MJ, Van Hardeveld C, Paulus WJ, Simonides WS (2004) Contractile arrest reveals calcium-dependent stimulation of SERCA2a mRNA expression in cultured ventricular cardiomyocytes. Cardiovasc Res 63:537-544

36. Walther T, Stepan H, Pankow K, Becker M, Schultheiss HP, Siems WE (2004) Biochemical analysis of neutral endopeptidase activity reveals independent catabolism of atrial and brain natriuretic peptide. Biol Chem 385:179-184

37. Wei CM, Heublein DM, Perella MA, Lerman A, Rodeheffer RJ, McGregor CG, Edwards WD, Schaff HV, Burnett JC Jr (1993) Natriuretic peptide system in human heart failure. Circulation 88:1004-1009 
38. Wilkins BJ, Dai YS, Bueno OF, Parsons SA, Xu J, Plank DM, Jones F, Kimball TR, Molkentin JD (2004) Calcineurin/NFAT coupling participates in pathological, but not physiological, cardiac hypertrophy. Circ Res 94:110-118
39. Ziolo MT, Lewandowski SJ, Smith JM, Romano FD, Wahler GM (2003) Inhibition of cyclic GMP hydrolysis with zaprinast reduces basal and cyclic AMP-elevated L-type calcium current in guinea-pig ventricular myocytes. Br J Pharmacol 138:986-994 